\title{
Rare Complication of Gallstone Disease:Gallbladder -Appendicular Fistula: Clinical Case Report
}

\author{
Yareshko NO, Mikheev IO*, Shabanov NA, Barska KS and Kanaki AV \\ Ukraine
}

*Corresponding author: Mikheev IO, Ukraine

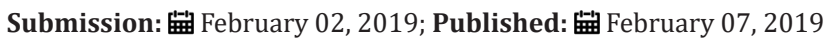

\section{Introduction}

Gallstone disease is one of the most common diseases detected, according to the literature, in $10-15 \%$ of the population [1-5]. According to the Center for Medical Statistics of the Ministry of Health of Ukraine, in recent years there has been a significant increase in the number of patients with Gallstone disease. Among rare complications cholelithiasis are isolated external biliary fistula, internal or cholecystodigestive fistulas, torakobiliary and bronchobiliary fistulas, cholecystocholedoheal fistula or Mirizzi syndrome, cholelithiasis small bowel obstruction, but also other types of bile fistula and micro or "large" choledocholithiasis, "wrinkled" gallbladder, calcification of the gallbladder [6].

Biliodigestive Fistulae (BDF), combined in the concept of "Internal Biliary Fistula", are rare and late complications of cholelithiasis. The basis of these diseases is a violation of the patency of the bile ducts. Due to inflammatory-degenerative changes between the gallbladder wall or the common bile duct on the one side, the wall of the follow organ on the other side (duodenum, small and large intestine, stomach), Biliodigestive fistulae is formed. A number of observations reveal a combination of two types of fistula.

A separate and rare problem in biliary surgery is biliodigestive fistulae. The BDF was first described by Bartholin in 1654 against the backdrop of a penetrating duodenal ulcer [7]. According to literary data, cholecystoduodenal (37.3-70\%), cholecystocolonic (3.4-21.5\%) and cholecystogastric fistula (3.3-15.6\%) less often choledochoduodenal (3-5\%) $[3,4,8,9]$ are shown. The main reasons for their formation are the complicated course of Gallstone disease (choledocholithiasis) (75-90\%), duodenal ulcer (5-6\%), Crohn's disease $[4,7]$. In the choledochoduodenal fistula, more often the fistula is located on the posterior wall of the duodenum, with choledocholithiasis in the distal parts of the common bile duct (CBD), and in duodenal ulcer in the proximal [7]. Clinical symptoms in internal biliary fistulas in general do not differ from diseases that occur with calculous cholecystitis and obstructive jaundice.

Differential diagnostics is usually performed with choledocholithiasis, cholangiocarcinoma, sclerosing cholangitis, malignant tumor of the gallbladder, pancreas, chronic pancreatitis. Established more accurate clinical and anamnestic characteristics of biliary tract fistulas: gallstone disease in history, weight loss, jaundice, recurrent chills, bouts of pain up to three to four times a year, discomfort in the right hypochondrium $[3,4]$. The peculiarity of the clinical course of biliodigestive fistulas is intermittent symptom of severe cholangitis due to the reflux of intestinal contents in the biliary system, as well as loss of body weight, signs of dyspepsy, and abundant liquid stool. Given the prevalence of gallstones and the danger of this, although rare, but it's serious complication, such as the formation of biliodigestive fistula, we give the following clinical observation (Figure 1).

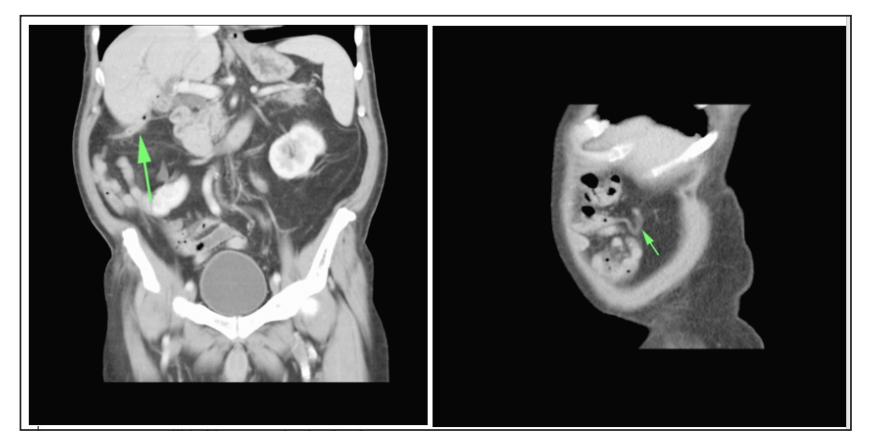

Figure 1: CT scan: Gallbladder-Appendicular Fistula.

Patient H, 69 years old, was taken to City Clinical Hospital from the district, hospitalized with a preliminary diagnosis: Pancreatic head disease. Choledocholithiasis. Cholangitis Mechanical jaundice. According to the patient, he has been ill for two weeks, when, after an error in the patient's diet, pain in the right hypochondrium began to bother, in the evening the body temperature rose to $37.5^{\circ}$ $38.0^{\circ} \mathrm{C}$ with chills, loose stools. He did not seek medical help, was treated on his own, took antipyretic and antispasmodic drugs. The pain syndrome was stopped, but the fever with chills remained, the yellowness of the skin and sclera, darkening of the urine, bleached feces appeared. The patient was sent to the surgical hospital of the city clinical hospital №3, hospitalized on the $15^{\text {th }}$ day of the disease [1]. 
When inspecting the patient's condition of moderate severity. The tongue was dry, white coated. Skin and visible mucous icteric. Pulse 90 per minute, satisfactory properties. Blood pressure $18.7 / 10.7 \mathrm{kPa}(140 / 80 \mathrm{mmHg}$. Art.). In the lungs vesicular breathing, no wheezing. The abdomen is soft, with painful palpation in the right hypochondrium. The liver is enlarged, protrudes by $1.5 \mathrm{~cm}$ from under the edge of the costal arch. The spleen is not palpable.

\section{The Patient is Examined Laboratory and Instrumentally}

Laboratory data. Complete blood count: red blood cells 3.7 - 1012/l, Hb 133g/l, leukocytes 10.7 • 109/l, neutrophils 63\%. Biochemical analysis of blood: total protein $64.2 \mathrm{~g} / \mathrm{l}$, total bilirubin $168.2 \mu \mathrm{mol} / \mathrm{l}$, urea $6.3 \mathrm{mmol} / \mathrm{l}$, creatinine $117 \mu \mathrm{mol} / \mathrm{l}$, ALT 17 units $/ \mathrm{l}$ Ultrasonography of the abdominal organs determines diffuse changes in the liver, scar-wrinkled gallbladder, dilatation inside and extrahepatic bile ducts. Choledocholithiasis.

Multispiral computed tomography of the abdominal cavity and retroperitoneal space: signs of the gallstone disease, the gallbladder in a shriveled state, the walls are not clearly differentiated, inclusions suspicious for gas bubbles are visualized in the projection of the lumen. Choledocholithiasis. Biliary hypertension, initial signs of ductal hypertension with a block at the level of major duodenal papilla. Diffuse changes in the parenchyma of the liver and pancreas. In the area of the dome of the cecum, a worm-shaped process up to $16 \mathrm{~cm}$ in size is visualized, which has a subhepatic arrangement and is intimately connected with the top of the gallbladder (fistula?). Incomplete doubling of the pyelocaliceal system of the right kidney.

On the third day from the moment of hospitalization, after the preoperative preparation, the patient was operated on: an upper-midline laparotomy was performed with a bypass of the navel on the left. Then revision of the abdominal cavity was determined by diffusely altered, enlarged liver due to both lobes, pasty, full-blooded, the edges of the liver were rounded. Common bile duct expanded to $15 \mathrm{~mm}$ in diameter. In the area of the right hypochondrium, an infiltrate is determined, consisting of the gallbladder, the caecum dome and the appendix. When exposing the infiltrate, it was found that the apex of the appendix was intimately adhered to the bottom of the gallbladder. In the area of the bottom of the bladder, an opening up to $3 \mathrm{~mm}$ in diameter is defined, in the area of the apex of the appendix, an opening up to $2 \mathrm{~mm}$ in diameter is defined with a zone of perifocal inflammation and a pronounced granulation shaft (according to multispiral computer tomography, ultrasound investigation is a biliodigestive fistula).

The gallbladder is reduced in size, the walls of the bladder are rigid, thickened, scar-wrinkled, small calculi in the lumen. Selected cystic duct, cystic artery, the latter are tied up crossed. Performed cholecystectomy from the cervix. The dome of the cecum with the appendix is visualized. The latter is up to $16 \mathrm{~cm}$ long, thickened, tense, with vascular injection. The mesentery of the appendix is fractionally ligated with flashing. Appendectomy was produced with immersion of the stump of the process in the pouch and Z-stitches after treatment with iodine. Duodenum is mobilized by Kocher. There was palpation of all parts of the pancreas is homogeneous, the size is within normal limits.
Inthesupraduodenalpartofthecholedoch,choledocholithotomy was performed. Two calculi were removed from the distal part of choledoch with sizes 9 and $11 \mathrm{~mm}$. Common bile duct was drained by Kerr. Choledoch was closed by suture. Completed water load, the seams are sealed. The abdominal cavity is drained and drained. One drainage and rubber graduate are installed in the right subhepatic space. Hemostasis control is dry. Made wound closure of the anterior abdominal wall. After the operation, the patient was kept for two days in the intensive care unit and intensive care unit. He received conservative therapy, dressings were made. Drainage common bile duct separated to $150-200 \mathrm{ml}$ of bile. On the drainage from the abdominal cavity scant serous hemorrhagic discharge.

On the third day, the patient was transferred to the ward of the first surgical department. Drainage and rubber graduate removed from the abdominal cavity, the common bile duct drainage 100$150 \mathrm{ml}$ bile. The postoperative period was uneventful. The stitches were removed for 7-8days. Drainage Kerr removed on the $8^{\text {th }}$ day. Primary wound healing. On the ninth day of hospital stay, a followup ultrasound investigation was performed, conclusion: no organic pathology was detected. The patient was discharged in satisfactory condition.

\section{Final Diagnosis}

Gallstone disease, cicatricial-wrinkled gallbladder. Choledocholithiasis. Bladder appendicular fistula. Cholangitis Mechanical jaundice. Viewed after one month-healthy. Thus, before the operation and intraoperatively, we diagnosed a gallbladder appendicular fistula. In the medical literature reports of such biliodigestive fistula we have not been found.

\section{Conclusion}

The given clinical observation shows the possibilities of successful application of a complex of methods of radiation diagnostics in the detection of biliodigestive fistula. Biliodigestive fistulae (BDF) is a serious complication whose early diagnosis is very difficult. ERCP, MSCT, and ultrasound of the abdominal organs showed the greatest diagnostic efficacy.

\section{References}

1. Beltran MA, Csendes A, Cruces KS (2008) The relationship of Mirizzi syndrome and cholecystoenteric fistula: validation of a modified classification. World J Surg 32(10): 2237-2243.

2. Stagnitti F, Mongardini M, Schillaci F, Dall olio D, De pascalis M, et al. (2000) Spontaneous biliodigestive fistulae. The clinical considerations, surgical treatment and complications. G Chir 21(3): 110-117.

3. Mithani R, Schwesinger WH, Bingener J, Sirinek R, Gross GW (2008) The Mirizzi syndrome: multidisciplinary management promotes optimal outcomes. J Gastrointest Surg 12(6): 1022-1028.

4. Yamashita H, Chijiiwa K, Ogawa Y, Kuroki S, Tanaka M (1997) The internal biliary fistula-reappraisal of incidence, type, diagnosis and management of 33 consecutive cases. HPB Surg 10(3): 143-147.

5. Bedin VV, Zarutskaya NV, Pelts VA (2006) Ten-year experience of surgical treatment of patients with biliodigestive and cholecystocholedocheal fistulas. Annals of Surgical Hepatology 11(3): 72.

6. Topchiashvili ZA, Kaprov IB (1988) Spontaneous internal biliary fistulas. Tbilisi Ganatleba, p. 132. 
7. Glabai VP, Askerkhanov RG (2006) Surgical treatment of non-standard complications of a long-existing cholelithiasis. Annals of Surgical Hepatology 11(3): 78-79.

8. Mallikarjunappa B, Ashish SR (2013) Choledochoduodenal fistula: A rare case report with review of literature. JIMSA 26: 4.
9. Topal U, Savci G, Sadikoglu MY, Tuncel E (1997) Choledochoduodenal fistula secondary to duodenal peptic ulcer. A case Report. Acta Radiol 38(6): 1007-1009.

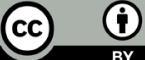

Creative Commons Attribution 4.0 International License

For possible submissions Click Here

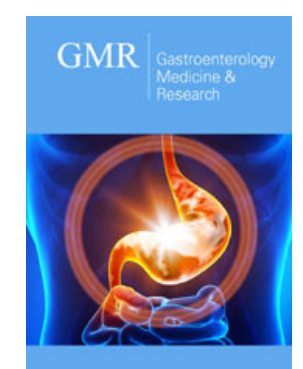

\section{Gastroenterology Medicine \& Research}

\section{Benefits of Publishing with us}

- High-level peer review and editorial services

- Freely accessible online immediately upon publication

- Authors retain the copyright to their work

- Licensing it under a Creative Commons license

- Visibility through different online platforms 